\title{
Value of ultrasonography in the diagnosis of primary hepatic carcinoma and thyroid carcinoma
}

\author{
LEI WANG $^{1}$, XIAOJIE PAN ${ }^{1}$ and JIANBING QIN ${ }^{2}$ \\ ${ }^{1}$ Ultrasound Department, Liaocheng People's Hospital; ${ }^{2}$ Department of Pathology, \\ Liaocheng Third People's Hospital, Liaocheng, Shandong 252000, P.R. China
}

Received April 16, 2018; Accepted July 26, 2018

DOI: $10.3892 / \mathrm{ol} .2018 .9272$

\begin{abstract}
The present study explored the value of ultrasonography in the diagnosis of primary hepatic carcinoma (PHC) and thyroid carcinoma (TC) by assessing their sonographic features. A total of 426 patients diagnosed with liver space-occupying lesions by ultrasonic examination admitted to Liaocheng People's Hospital from March 2014 to October 2017 were enrolled in this study. These patients were divided into two groups: A total of 226 patients with 237 foci in the PHC group and 200 patients with 216 foci in the benign liver lesion group. During the same period, 367 patients diagnosed with thyroid nodules (382 nodules) by ultrasonic examination were also enrolled in this study. These patients were divided into further two groups: A total of 193 patients with 203 nodules in the TC group and 174 patients with 179 nodules in the benign thyroid nodule group. Two-dimensional and color Doppler ultrasonography were performed on all the patients in the four groups. Differences in the sonographic features such as focus morphology, focus size, internal echo, halo and blood flow distribution were statistically significant between patients in the PHC and the benign liver lesion group $(p<0.001)$. Differences in the sonographic features such as nodule boundary, nodule size, internal echo, microcalcification, lymph node status and blood flow were statistically significant between patients in the TC and the benign thyroid nodule group $(\mathrm{p}<0.01)$. PHC can be differentiated from benign liver lesions by evaluation of focus morphology, focus size, internal echo, halo, and blood flow. TC can be differentiated from benign thyroid nodules by evaluation of nodule boundary, nodule size, internal echo, microcalcification, lymph node status, and blood flow. Ultrasonic diagnosis of PHC and TC is not only accurate, but also convenient, fast, cost-efficient and non-invasive. Thus,
\end{abstract}

Correspondence to: Dr Xiaojie Pan, Ultrasound Department, Liaocheng People's Hospital, 67 Dongchang West Road, Liaocheng, Shandong 252000, P.R. China

E-mail: pcc4fe@163.com

Key words: two-dimensional ultrasonography, color Doppler ultrasonography, primary hepatic carcinoma, thyroid carcinoma, diagnostic value application of ultrasonography in the diagnosis of PHC and TC should be expanded for the benefits of patients.

\section{Introduction}

Primary hepatic carcinoma (PHC) is a common gastrointestinal cancer in humans. There are approximately 600,000 new patients diagnosed with $\mathrm{PHC}$ each year worldwide. Its mortality ranks third among human malignancies (1). Thyroid carcinoma (TC) is the most common cancer of the endocrine system. It is a malignancy derived from the thyroid epithelial cells. Annual new patients diagnosed with TC accounts for $1 \%$ of all patients newly diagnosed with malignant tumors (2). Along with the economic and social development, the incidence of PHC and TC has risen year by year in recent decades, and patient age tends to be younger. In the past, the patients were often in the advanced stage of the disease when diagnosed, as a result of fast progression of the disease and lack of specific clinical symptoms for early diagnosis $(3,4)$. Therefore, early accurate diagnosis of PHC and TC is particularly important, which can directly facilitate timely development of the patient treatment plan and promise a good prognosis and quality of life. According to literature, the 5-year survival rates of PHC and TC were approximately 70 and $80 \%$, respectively, after early surgical treatment $(5,6)$. Diagnosis based on pathological tests is the most common practice for cancer diagnosis. This approach has a high diagnostic rate, but also has some disadvantages. The main drawback is its invasiveness which is necessary for tissue harvesting from the patient. Therefore, a pathological test cannot be performed routinely as an early screening test due to the invasiveness (7). As the imaging technologies advance, two-dimensional and color Doppler ultrasonography have been gradually adopted in the early screening and diagnosis of malignant tumors. Using the ultrasonography, the number and size of tumor foci, as well as their location and relationship with adjacent tissues, can be observed clearly in the tumor mass. Ultrasonic diagnosis is non-invasive, reproducible and cost-efficient $(8,9)$. Due to these favorable features, ultrasonography has been playing an important role in the clinic. However, combination of two-dimensional and color Doppler ultrasonography has rarely been reported in the early screening and diagnosis of PHC and TC. In this study, both two-dimensional and color Doppler ultrasonography 
were performed on 426 patients with liver space-occupying lesions and 367 patients with thyroid nodules. The diagnostic results based on the sonographic features were compared with the postoperative pathological test results, aiming to explore the applicable value of simultaneous use of two ultrasound techniques in the differential diagnosis of liver space-occupying lesions and thyroid nodules.

\section{Patients and methods}

Patients. Four hundred and twenty six patients diagnosed with liver space-occupying lesions (453 foci) by ultrasonic examination, who were admitted to Liaocheng People's Hospital (Liaocheng, China) from March 2014 to October 2017, were enrolled in this study. These patients were divided into two groups: 226 patients with 237 foci in the PHC group and 200 patients with 216 foci in the benign liver lesion group. There were 141 males and 85 females, aged 23-69 years, in the PHC group. Of the 237 cancer foci in the PHC group, 197 were hepatocellular carcinoma of origin, and 40 were cholangiocellular carcinoma of origin. There were 109 males and 91 females, aged 25-73 years, in the benign liver lesion group. During the same period, 367 patients diagnosed with thyroid nodules (382 nodules) by ultrasonic examination in Liaocheng People's Hospital were also enrolled in this study. These patients were divided into further two groups: 193 patients with 203 nodules in the TC group and 174 patients with 179 nodules in the benign thyroid nodule group. There were 35 males and 158 females, aged 24-76 years, in the TC group. Among the 203 cancer nodules, 3 were metastatic TC of origin, 7 were anaplastic TC of origin, 15 were of medullary TC of origin, 34 were follicular TC, and 144 were papillary TC of origin. There were 21 males and 153 females, aged 21-69 years, in the benign thyroid nodule group. Among the 179 benign nodules, 79 were benign thyroid tumor of origin, and 100 were nodular goiter of origin.

Inclusion and exclusion criteria. The following patients were included in this study: Patients with clear primary lesions diagnosed by histopathological and cytological tests, as well as imaging with MRI (10) and patients who had complete ultrasonic examination record. Patients who had the following conditions were excluded from this study: Severe heart failure, severe lung, kidney or hematopoietic dysfunction; with a history of previous mental disease and with a family history of mental disease. This study was approved by Liaocheng People's Hospital's Ethics Committee. All the patients or their families signed the informed consent.

Methods. Ultrasonic examination was performed using a GE Logiq E9 color Doppler ultrasound system. The system was equipped with a GE 3.5C convex array transducer probe, and the probe had a frequency of 6-9 MHz.

Liver examination method. The patient fasted for $8 \mathrm{~h}$ prior to the examination. At the time of examination, the patient was placed in the supine position. After the ultrasound system was adjusted to the right parameter settings, a 2D multi-sectional examination of the whole liver was performed. If necessary, the patient's position was changed so that the sonographic features
Table I. Baseline clinical data of patients in the PHC and benign liver lesion group.

\begin{tabular}{|c|c|c|c|c|}
\hline \multirow[b]{2}{*}{ Items } & \multicolumn{2}{|c|}{ Groups } & \multirow[b]{2}{*}{ t value } & \multirow[b]{2}{*}{ P-value } \\
\hline & PHC & $\begin{array}{l}\text { Benign liver } \\
\text { lesion }\end{array}$ & & \\
\hline Patient no. & 226 & 200 & & \\
\hline \multicolumn{5}{|l|}{ Sex, n (\%) } \\
\hline Male & $141(62.39)$ & $109(54.50)$ & 2.724 & 0.115 \\
\hline Female & $85(37.61)$ & $91(45.50)$ & & \\
\hline Age, years & $49.6 \pm 13.3$ & $48.3 \pm 8.7$ & 1.177 & 0.239 \\
\hline \multicolumn{5}{|c|}{$\begin{array}{l}\text { Status of viral } \\
\text { hepatitis, n (\%) }\end{array}$} \\
\hline Yes & $143(63.27)$ & $108(54.00)$ & 3.771 & 0.061 \\
\hline No & $83(36.73)$ & $92(46.00)$ & & \\
\hline \multicolumn{5}{|c|}{$\begin{array}{l}\text { Status of } \\
\text { cirrhosis, n (\%) }\end{array}$} \\
\hline Yes & $33(14.60)$ & $21(10.50)$ & 1.613 & 0.243 \\
\hline No & $193(85.40)$ & $179(89.50)$ & & \\
\hline \multicolumn{5}{|l|}{$\begin{array}{l}\text { Status of } \\
\text { AFP, n (\%) }\end{array}$} \\
\hline Positive & $53(23.45)$ & $31(15.50)$ & 4.238 & 0.051 \\
\hline Negative & $173(76.55)$ & $169(84.50)$ & & \\
\hline
\end{tabular}

PHC, primary hepatic carcinoma; AFP, $\alpha$-fetoprotein.

of the lesions could be clearly observed. First, the liver was carefully inspected for any abnormality in size, shape, echo of liver parenchyma, liver capsule, blood vessels, and internal echo. After lesions were found, attention should be paid to the number, locations, morphology, boundary, internal and posterior echoes of the lesion foci. These sonographic features were recorded in detail. In addition, the ultrasonic blood flow distribution and spectrum were inspected as well. The images were saved.

Thyroid examination method. The patient was placed in the supine position with the neck fully exposed. The thyroid gland was scanned for transverse, longitudinal and oblique views. When a nodule was found, its size, morphology, parenchymal echo pattern, calcification, blood vessels and internal echo were carefully inspected. The lymph node status, as well as the ultrasonic blood flow distribution and spectrum, were inspected. The images of the blood flow distribution and spectrum were saved.

Statistical analysis. The statistical software SPSS 17.0 (SPSS, Inc., Chicago, IL, USA) was used for statistical analysis. The measurement data were expressed as mean \pm standard deviation (SD). The Chi-square test was used for comparison of the enumeration data between two groups, and the t-test was used for comparison of the measurement data between two groups. One way analysis of variance was used for data comparison between multiple groups and the post hoc test was Least Significant Difference. The difference was statistically significant at $\mathrm{p}<0.05$. 
Table II. Baseline clinical data of patients in the TC and benign thyroid nodule group.

\begin{tabular}{lcccc}
\hline & \multicolumn{4}{c}{ Groups } \\
\cline { 2 - 3 } Items & TC & Benign thyroid \\
nodule & t value & P-value \\
\hline Patient no. & 193 & 174 & & \\
Sex, n (\%) & & & & \\
Male & $35(18.13)$ & $21(12.07)$ & 2.604 & 0.112 \\
Female & $158(81.87)$ & $153(87.93)$ & & \\
Age, years & $47.1 \pm 12.8$ & $44.9 \pm 11.6$ & 1.719 & 0.086 \\
TSH (mU/l) & $1.73 \pm 1.15$ & $1.61 \pm 0.89$ & 1.109 & 0.268 \\
FT3 (mU/l) & $4.78 \pm 1.21$ & $4.63 \pm 0.73$ & 1.419 & 0.156 \\
FT4 (mU/l) & $17.38 \pm 3.74$ & $16.87 \pm 3.51$ & 1.343 & 0.18 \\
TPO-Ab (mU/l) & $217.62 \pm 127.82$ & $199.47 \pm 115.19$ & 1.423 & 0.155 \\
Tg-Ab (mU/l) & $81.56 \pm 31.73$ & $86.68 \pm 34.28$ & 1.486 & 0.138 \\
\hline
\end{tabular}

TC, thyroid carcinoma; TSH, thyroid-stimulating hormone; FT3, free triiodothyronine; FT4, free thyroxine; TPO-Ab, thyroid peroxidase antibody; $\mathrm{Tg}-\mathrm{Ab}$, thyroglobulin antibody.

Table III. Diagnosis of PHC using ultrasonography and pathological tests.

\begin{tabular}{lrcr}
\hline & \multicolumn{2}{c}{ Pathological tests } & \\
\cline { 2 - 3 } Items & PHC & $\begin{array}{c}\text { Benign liver } \\
\text { lesions }\end{array}$ & Total \\
\hline Ultrasonic diagnosis & & & \\
PHC & 177 & 58 & 235 \\
Benign liver lesions & 49 & 142 & 191 \\
Total & 226 & 200 & 426 \\
\hline
\end{tabular}

PHC, primary hepatic carcinoma.

\section{Results}

Baseline data of patients in the PHC and the benign liver lesion group. As shown in Table I, the differences in baseline clinical data such as sex, age, status of viral hepatitis, of cirrhosis, and of $\alpha$-fetoprotein (AFP) were not statistically significant between patients in the PHC and the benign liver lesion group $(\mathrm{p}>0.05)$.

Baseline data of patients in the TC and the benign thyroid nodule group. As shown in Table II, the differences in baseline clinical data such as sex, age, serum thyroid-stimulating hormone (TSH), serum free triiodothyronine (FT3), serum free thyroxine (FT4), serum thyroid peroxidase antibody (TPO-Ab) and serum thyroglobulin antibody $(\mathrm{Tg}-\mathrm{Ab})$ were not statistically significant between patients in the TC and the benign thyroid nodule group ( $\mathrm{p}>0.05)$.
Table IV. Sonographic features of 453 foci in patients with occupied liver space.

\begin{tabular}{|c|c|c|c|c|}
\hline \multirow[b]{2}{*}{$\begin{array}{l}\text { Sonographic } \\
\text { features }\end{array}$} & \multicolumn{2}{|c|}{ Groups } & \multirow[b]{2}{*}{$\chi^{2}$ value } & \multirow[b]{2}{*}{$\mathrm{P}$-value } \\
\hline & $\begin{array}{l}\text { PHC } \\
\mathrm{n}(\%)\end{array}$ & $\begin{array}{c}\text { Benign liver } \\
\text { lesion } \\
\mathrm{n}(\%)\end{array}$ & & \\
\hline Total foci & 237 & 216 & & \\
\hline \multicolumn{5}{|c|}{ Focus multiplicity } \\
\hline Single & $226(95.36)$ & $200(92.59)$ & 1.543 & 0.238 \\
\hline Multiple & $11(4.64)$ & $16(7.41)$ & & \\
\hline \multicolumn{5}{|c|}{ Focus morphology } \\
\hline Regular & $153(64.56)$ & $94(43.52)$ & 20.173 & $<0.001$ \\
\hline Irregular & $84(35.44)$ & $122(56.48)$ & & \\
\hline \multicolumn{5}{|c|}{ Focus boundary } \\
\hline Clear & $106(44.73)$ & $93(43.06)$ & 0.128 & 0.776 \\
\hline Vague & $131(55.27)$ & $123(56.94)$ & & \\
\hline \multicolumn{5}{|l|}{ Focus size, $\mathrm{cm}$} \\
\hline$\leq 3$ & $34(14.35)$ & $107(49.54)$ & 65.282 & $<0.001$ \\
\hline$>3$ & $203(85.65)$ & $109(50.46)$ & & \\
\hline \multicolumn{5}{|l|}{ Internal echo } \\
\hline Hypoechoic & $145(61.18)$ & $52(24.07)$ & 63.407 & $<0.001$ \\
\hline Isoechoic & $40(16.88)$ & $68(31.48)$ & & \\
\hline Hyperechoic & $52(21.94)$ & $96(44.44)$ & & \\
\hline \multicolumn{5}{|l|}{ Halo } \\
\hline Yes & $153(64.56)$ & $99(45.83)$ & 16.050 & $<0.001$ \\
\hline No & $84(35.44)$ & 117 (54.17) & & \\
\hline \multicolumn{5}{|l|}{$\begin{array}{l}\text { Lymph node } \\
\text { metastasis }\end{array}$} \\
\hline Yes & $23(9.70)$ & $16(7.41)$ & 0.758 & 0.407 \\
\hline No & $214(90.30)$ & $200(92.59)$ & & \\
\hline \multicolumn{5}{|c|}{$\begin{array}{l}\text { Blood flow } \\
\text { distribution lesions }\end{array}$} \\
\hline Grade I & $43(19.91)$ & $78(32.91)$ & 22.980 & $<0.001$ \\
\hline Grade II & $71(32.87)$ & $97(40.93)$ & & \\
\hline Grade III & $102(47.22)$ & $62(26.16)$ & & \\
\hline
\end{tabular}

PHC, primary hepatic carcinoma.

Diagnosis of PHC using ultrasonography. Among the 453 foci found in patients with liver space-occupying lesions, 237 were believed to be PHC of origin in 226 patients, and 216 were of benign liver lesion of origin in 200 patients, following confirmation by pathological tests. Of the 237 cancer foci, 197 were hepatocellular carcinoma of origin in 188 patients, and 40 were cholangiocellular carcinoma of origin in 38 patients. Of the 216 benign foci, 120 were hemangioma of origin in 114 patients, 62 were hyperplastic nodules of liver cirrhosis in 58 patients, 15 were hepatic abscess in 12 patients, and 19 were focal nodular hyperplasia of origin in 16 patients. As shown in Table III, the sensitivity, specificity and accuracy of the 


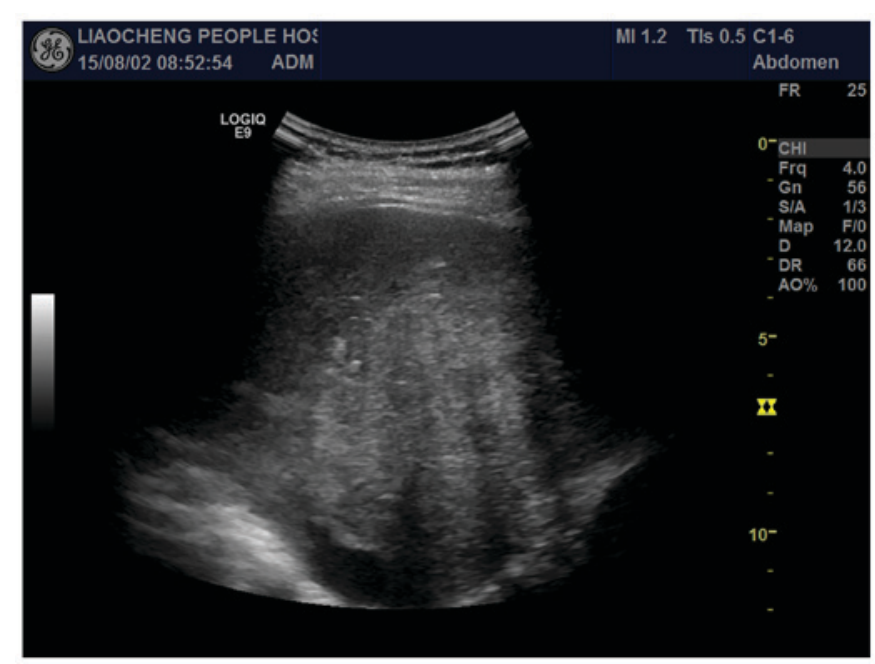

Figure 1. Sonographic features of PHC: Hypoechoic pattern, clear halo sign, absence of lateral acoustic shadowing, without noticeable change in posterior echo, and heterogeneous internal echo. PHC, primary hepatic carcinoma.

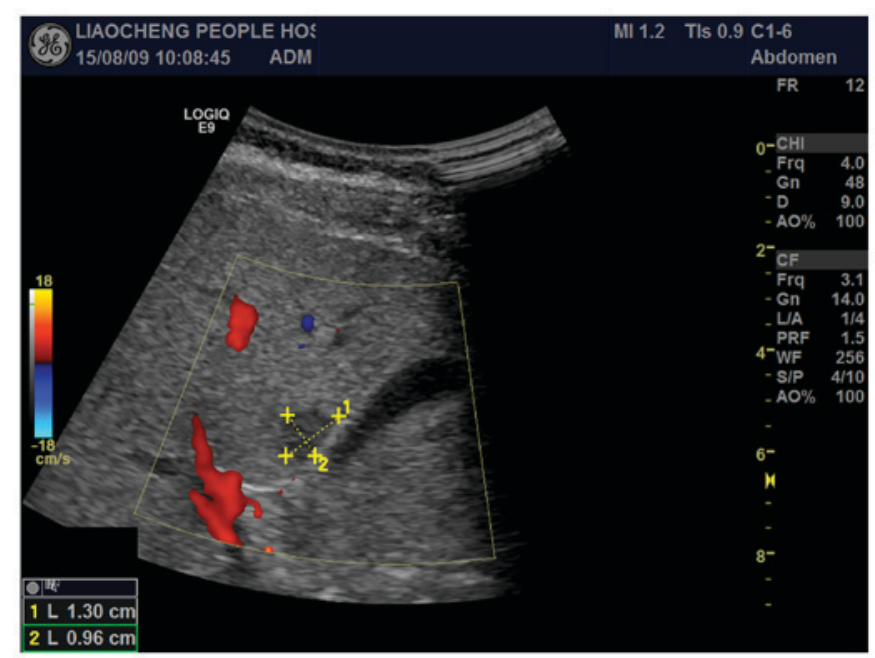

Figure 2. Sonographic features of PHC: Hypoechoic pattern, unclear halo sign, blurred boundary, presence of lateral acoustic shadowing, heterogeneous internal echo, and visible rich blood flow signal. PHC, primary hepatic carcinoma.

ultrasonic diagnosis of PHC were $78.32 \%$ (177/226), $71.00 \%$ (142/200) and 74.88\% (319/426), respectively.

Sonographic features of PHC. As shown in Table IV, the differences in the sonographic features such as focus morphology, focus size, internal echo pattern, halo and blood flow distribution were statistically significant between patients in the PHC and the benign liver lesion group $(\mathrm{p}<0.001)$. The major sonographic features of PHC included regular shape in focus morphology, $>3 \mathrm{~cm}$ in focus size, hypoechoic internal echo, visible thin halo signs, and rich internal blood flow. Sonographic features of PHC are shown in Figs. 1 and 2.

Diagnosis of TC using ultrasonography. Among the 382 nodules found in patients with thyroid nodules, 203 were believed to be TC origin in 193 patients, and 179 were believed to be benign thyroid nodules of origin in 174 patients, following
Table V. Diagnosis of TC using ultrasonography and pathological tests.

\begin{tabular}{|c|c|c|c|}
\hline \multirow[b]{2}{*}{ Items } & \multicolumn{2}{|c|}{ Pathological tests } & \multirow[b]{2}{*}{ Total } \\
\hline & $\mathrm{TC}$ & $\begin{array}{l}\text { Benign thyroid } \\
\text { nodules }\end{array}$ & \\
\hline \multicolumn{4}{|l|}{ Ultrasonic diagnosis } \\
\hline $\mathrm{TC}$ & 153 & 42 & 195 \\
\hline Benign thyroid nodules & 40 & 132 & 172 \\
\hline Total & 193 & 174 & 367 \\
\hline
\end{tabular}

TC, thyroid carcinoma.

confirmation by pathological tests. Of the 203 cancer nodules, 3 were metastatic TC of origin in 3 patients, 7 were anaplastic TC of origin in 7 patients, 15 were medullary TC in 15 patients, 34 were the follicular TC of origin in 30 patients, and 144 were papillary TC in 138 patients. Of the 179 benign nodules, 79 were the benign thyroid tumor of origin in 77 patients, and 100 were nodular goiter of origin in 97 patients. As shown in Table V, the sensitivity, specificity and accuracy of the ultrasonic diagnosis of TC were $79.27 \%$ (153/193), $75.86 \%$ $(132 / 174)$ and $77.65 \%$ (285/367), respectively.

Sonographic features of TC. As shown in Table VI, the differences in the sonographic features such as nodule boundary, nodule size, internal echo, microcalcification, lymph node status and blood flow distribution were statistically significant between patients in the TC and the benign thyroid nodule group $(p<0.01)$. The major sonographic features of TC included blurred nodule boundary, $>1 \mathrm{~cm}$ in nodule size, hypoechoic internal echo pattern, visible microcalcification, enlarged lymph nodes, and rich internal blood flow. Sonographic features of TC are shown in Figs. 3 and 4.

\section{Discussion}

The incidence of $\mathrm{PHC}$ and $\mathrm{TC}$ has risen in recent years. However, the pathogenesis of the diseases has not been elucidated. PHC and TC are often in advanced stages when there are clear symptoms and the patients seek medical assistance due to no symptoms in the early stages, which increases the difficulty of clinical intervention $(11,12)$. Therefore, early diagnosis of PHC and TC, as well as timely effective treatments, is of great significance to patients' survival and prognosis. As medical technologies are advancing, two-dimensional and color Doppler ultrasonography have gradually been applied clinically to the early screening of malignant tumors. The two ultrasound-based technologies have high resolution, and can clearly show the location, size, morphology, internal echo, and blood flow distribution of lesions. In the clinic, ultrasonography has become the preferred imaging method for malignant tumors, and is playing an important role in severity assessment of malignant tumors and decision making of treatment plan, as well as prediction of prognosis $(13,14)$. 
Table VI. Sonographic features of 382 nodules in patients with thyroid nodules.

\begin{tabular}{|c|c|c|c|c|}
\hline \multirow[b]{2}{*}{$\begin{array}{l}\text { Sonographic } \\
\text { features }\end{array}$} & \multicolumn{2}{|c|}{ Groups } & \multirow[b]{2}{*}{$\chi^{2}$ value } & \multirow[b]{2}{*}{ P-value } \\
\hline & $\begin{array}{c}\mathrm{TC} \\
\mathrm{n}(\%)\end{array}$ & $\begin{array}{c}\text { Benign thyroid } \\
\text { nodule } \\
\text { n }(\%)\end{array}$ & & \\
\hline Total nodules & 203 & 179 & & \\
\hline \multicolumn{5}{|c|}{ Nodule multiplicity } \\
\hline Single & $193(95.07)$ & $174(97.21)$ & 1.168 & 0.306 \\
\hline Multiple & $10(4.93)$ & $5(2.79)$ & & \\
\hline \multicolumn{5}{|c|}{ Nodule morphology } \\
\hline Regular & $139(68.47)$ & $116(64.80)$ & 0.557 & 0.514 \\
\hline Irregular & $64(31.53)$ & $63(35.20)$ & & \\
\hline \multicolumn{5}{|c|}{ Nodule boundary } \\
\hline Clear & $66(32.51)$ & $26(14.53)$ & 16.833 & $<0.001$ \\
\hline Vague & $137(67.49)$ & $153(85.47)$ & & \\
\hline \multicolumn{5}{|c|}{ Nodule size, $\mathrm{cm}$} \\
\hline$\leq 1$ & $79(38.92)$ & $36(20.11)$ & 16.775 & $<0.001$ \\
\hline$>1$ & $124(61.08)$ & $143(79.89)$ & & \\
\hline \multicolumn{5}{|l|}{ Internal echo } \\
\hline Hypoechoic & $160(78.82)$ & $50(27.93)$ & 99.518 & $<0.001$ \\
\hline Isoechoic & $5(2.46)$ & $16(8.94)$ & & \\
\hline Hyperechoic & $38(18.72)$ & $113(63.13)$ & & \\
\hline \multicolumn{5}{|c|}{ Microcalcification } \\
\hline Yes & $77(37.93)$ & $45(25.14)$ & 7.160 & 0.008 \\
\hline No & $126(62.07)$ & $134(74.86)$ & & \\
\hline \multicolumn{5}{|c|}{$\begin{array}{l}\text { Enlarged lymph } \\
\text { nodes }\end{array}$} \\
\hline Yes & $84(41.38)$ & $38(21.23)$ & 17.768 & $<0.001$ \\
\hline No & $119(58.62)$ & $141(78.77)$ & & \\
\hline \multicolumn{5}{|l|}{$\begin{array}{l}\text { Blood flow } \\
\text { distribution }\end{array}$} \\
\hline Grade I & $53(26.11)$ & $44(24.58)$ & 6.464 & 0.039 \\
\hline Grade II & $38(18.72)$ & $53(29.61)$ & & \\
\hline Grade III & $112(55.17)$ & $82(45.81)$ & & \\
\hline
\end{tabular}

TC, thyroid carcinoma.

Two-dimensional and color Doppler ultrasonography have been playing an important role in the clinical screening and diagnosis of malignant tumors. Two-dimensional ultrasonography can clearly show the specific location, size and morphology of lesions. Color Doppler ultrasonography has a high diagnostic value in differentiating benign and malignant lesions in patients with rich blood flow in the liver (15). In this study, the sensitivity, specificity and accuracy of the ultrasonic diagnosis of PHC were 78.32, 71.00 and 74.88\%, respectively. Through analysis of the sonograms, most of the PHC foci were found to be in a regular shape and have a diameter of $>3 \mathrm{~cm}$. Narrow halo signs were visible around the lesions. The lesioned tissue was homogeneous in composition, consisting of densely packed cancer cells. A high-velocity and

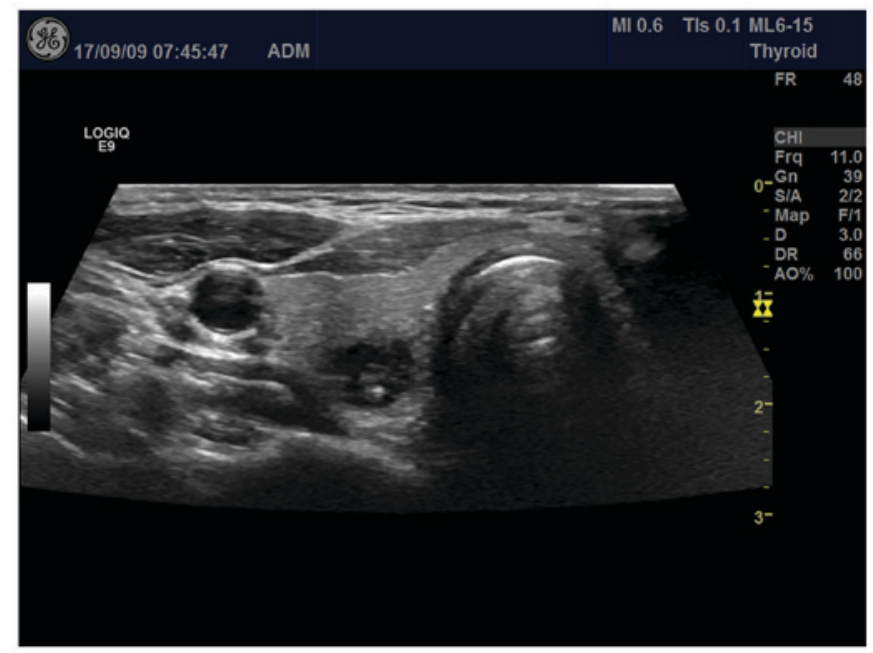

Figure 3. Sonographic features of TC: Blurred boundary, nodule size of $>1 \mathrm{~cm}$, and clustered microcalcifications. TC, thyroid carcinoma.

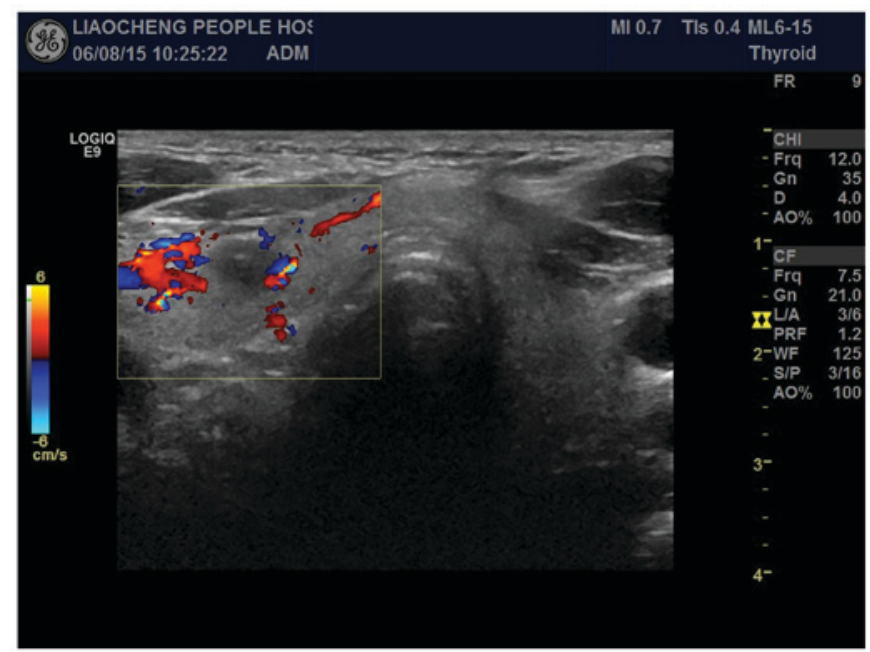

Figure 4. Sonographic features of TC: Hypoechoic pattern, blurred boundary, irregular morphology, scattered microcalcifications, and locally rich blood flow. TC, thyroid carcinoma.

low-impedance blood flow spectrum was observed, indicating a rich blood flow inside the lesioned tissue. Enlarged arterial branches and increased blood flow were observed around the tumor. However, some lesions of small hepatocellular carcinoma showed an isoechoic internal echo texture, and appeared to have no halo sign and no mosaic pattern. Missed diagnosis and misdiagnosis easily occur under these circumstances. Therefore, precautions were taken in the process to avoid diagnostic errors. In this study, the differences in the sonographic features such as focus morphology, focus size, internal echo, halo and blood flow distribution were statistically significant between patients in the PHC and the benign liver lesion group $(\mathrm{p}<0.001)$. This finding suggested that PHC can be differentiated from benign liver lesions by evaluation of focus morphology, focus size, internal echo, halo, and blood flow distribution. The differential diagnosis had a good diagnostic rate. In a similar study reported by Bhartia et al, lesions of PHC in 316 patients showed irregular morphology, hypoechoic internal echo texture, and homogeneity in composition (16). 
The reported differential diagnosis of PHC also had a good diagnostic rate.

Two-dimensional and color Doppler ultrasonography are the most commonly used techniques in diagnosis of TC. Al-Hilli et al reported that sonographic features, such as irregular morphology, unclear boundary, aspect ratio of $\geq 1$, hypoechoic internal echo, calcification and internal low blood supply, can be used to differentiate malignant thyroid nodules from benign ones (17). Especially, the three sonographic features, i.e., unclear boundary, aspect ratio of $\geq 1$ and calcification, were regarded as typical of thyroid malignancies (17). In this study, the sensitivity, specificity and accuracy of the ultrasonic diagnosis of TC were 79.27, 75.86 and $77.65 \%$, respectively. Through analysis of the sonograms, most of the TC nodules were found to have an unclear boundary, a size of $>1 \mathrm{~cm}$, and show a hypoechoic internal echo texture, microcalcifications, rich internal blood flow, abnormal blood vessels, and internal enlarged arteries. In addition, tumor cells were large and overlapping, and had little interstitial fluid. There were no interfaces allowing strong reflection. Some thyroid follicular and medullary carcinomas showed a hyperechoic internal echo texture, regular morphology and a clear boundary. Cystic lesions or necrosis were found in large cancer tissues. The calcification was deposition of calcium salts due to proliferation of fibrous components and blood vessels while tumor cells were rapidly growing. It may also be the calcified substances formed in tumor cell metabolism (18). When calcification is found, much attention should be paid to the possible thyroid malignancy. Fukuoka et al reported that calcification was closely associated with papillary TC and represented the major sonographic feature in its ultrasonography (19). Lymph node metastasis was commonly observed in papillary TC, presenting typical sonographic features such as enlarged lymph nodes, a heterogeneous internal echo texture, rich and disorderly blood flow, and calcification. In this study, the differences in the sonographic features such as nodule boundary, nodule size, internal echo pattern, microcalcification, lymph node status and blood flow distribution were statistically significant between patients in the TC and the benign thyroid nodule group $(\mathrm{p}<0.01)$. This finding suggested that TC can be differentiated from benign thyroid nodules by evaluation of nodule boundary, nodule size, internal echo pattern, microcalcification, lymph node status, and blood flow distribution. This differential diagnosis had a good diagnostic rate. Our results were different from those in a recent report, in which the ultrasonic diagnosis using high frequency color Doppler ultrasonography gave low sensitivity, specificity and accuracy $(52.4,43.8$ and $54.9 \%$, respectively) in 415 patients with thyroid nodules. In addition, the rate of missed diagnosis and misdiagnosis was high (20). The discrepancy might be due to differences in subjects enrolled in the studies and in instruments used. Further studies may be needed to validate the differential diagnosis.

To ensure reliability of the research results in this study, a large number of subjects were recruited, following the strict inclusion and exclusion criteria. As a diagnostic technique, ultrasonography is convenient, fast, cost-efficient and non-invasive, and has high diagnostic rate. Therefore, in the clinic it is the preferred imaging diagnostic tool for malignant tumors. However, there were still some cases of missed diagnosis and misdiagnosis for PHC and TC in this study. The sonographic features, as well as diagnostic decisions, were susceptible to various factors such as obesity, internal gas, breathing, angles, and body position. Thus, ultrasonography still had some limitations in the diagnosis of liver and thyroid diseases. It is hoped that in the near future a more effective, fast and non-invasive way could be found in the screening and diagnosis of PHC and TC.

In conclusion, PHC can be differentiated from benign liver lesions by evaluation of focus morphology, focus size, internal echo pattern, halo, and blood flow distribution. TC can be differentiated from benign thyroid nodules by evaluation of nodule boundary, nodule size, internal echo pattern, microcalcification, lymph node status, and blood flow distribution. Ultrasonic diagnosis of PHC and TC is not only accurate, but also convenient, fast, cost-efficient and non-invasive. Thus, application of ultrasonography in the diagnosis of PHC and TC should be expanded for the benefit of patients.

\section{Acknowledgements}

Not applicable.

\section{Funding}

No funding was received.

\section{Availability of data and materials}

The datasets used and/or analyzed during the present study are available from the corresponding author on reasonable request.

\section{Authors' contributions}

LW drafted this manuscript. LW and XP were mainly devoted on liver ultrasonic examination. JQ helped with thyroid ultrasonic examination. All authors read and approved the final manuscript.

\section{Ethics approval and consent to participate}

The study was approved by the Ethics Committee of Liaocheng People's Hospital, (Liaocheng, China). Signed written informed consents were obtained from the patients or guardians.

\section{Patient consent for publication}

Not applicable.

\section{Competing interests}

The authors declare that they have no competing interests.

\section{References}

1. Bhaijee F, Krige JE, Locketz ML and Kew MC: Liver resection for non-cirrhotic hepatocellular carcinoma in South African patients. S Afr J Surg 49: 68-74, 2011.

2. Schlumberger M, Elisei R, Müller S, Schöffski P, Brose M, Shah M, Licitra L, Krajewska J, Kreissl MC, Niederle B, et al: Overall survival analysis of EXAM, a phase III trial of cabozantinib in patients with radiographically progressive medullary thyroid carcinoma. Ann Oncol 28: 2813-2819, 2017. 
3. Khalaf N, Ying J, Mittal S, Temple S, Kanwal F, Davila J and El-Serag HB: Natural history of untreated hepatocellular carcinoma in a US cohort and the role of cancer surveillance. Clin Gastroenterol Hepatol 15: 273-281.e1, 2017.

4. Liu J, Marcaccio MJ, Young JE, Aziz T, Wat J and Asa SL: Pancreatic struma with papillary thyroid carcinoma: A diagnostic dilemma. Endocr Pathol 28: 91-94, 2017.

5. Sia D, Villanueva A, Friedman SL and Llovet JM: Liver cancer cell of origin, molecular class, and effects on patient prognosis. Gastroenterology 152: 745-761, 2017.

6. Elisei R, Schlumberger MJ, Müller SP, Schöffski P, Brose MS, Shah MH, Licitra L, Jarzab B, Medvedev V, Kreissl MC, et al: Cabozantinib in progressive medullary thyroid cancer. J Clin Oncol 31: 3639-3646, 2013.

7. Zhou J, Luo Y,Ma BY, Ling WW and Zhu XL: Contrast-enhanced ultrasound diagnosis of hepatic metastasis of concurrent medullary-papillary thyroid carcinoma: A case report. Medicine (Baltimore) 96: e9065, 2017.

8. Li F, Han J, Han F, Wang JW, Luo RZ, Li AH and Zhou JH: Combined hepatocellular cholangiocarcinoma (biphenotypic) tumors: Potential role of contrast-enhanced ultrasound in diagnosis. AJR Am J Roentgenol 209: 767-774, 2017.

9. Hong YR, Luo ZY, Mo GQ, Wang P, Ye Q and Huang PT: Role of contrast-enhanced ultrasound in the pre-operative diagnosis of cervical lymph node metastasis in patients with papillary thyroid carcinoma. Ultrasound Med Biol 43: 2567-2575, 2017.

10. Xu B, Scognamiglio T, Cohen PR, Prasad ML, Hasanovic A, Tuttle RM, Katabi N and Ghossein RA: Metastatic thyroid carcinoma without identifiable primary tumor within the thyroid gland: A retrospective study of a rare phenomenon. Hum Pathol 65: 133-139, 2017.

11. Kitahata S, Hiraoka A, Kudo M, Murakami T, Ochi M, Izumoto $\mathrm{H}$, Ueki $\mathrm{H}$, Kaneto $\mathrm{M}$, Aibiki $\mathrm{T}$, Okudaira $\mathrm{T}$, et al: Abdominal ultrasound findings of tumor-forming hepatic malignant lymphoma. Dig Dis 35: 498-505, 2017.

12. Gannon AW, Langer JE, Bellah R, Ratcliffe S, Pizza J, Mostoufi-Moab S, Cappola AR and Bauer AJ: Diagnostic accuracy of ultrasound with color flow Doppler in children with thyroid nodules. J Clin Endocrinol Metab: Mar 12, 2018 (Epub ahead of print).

13. Ling W, Qiu T, Ma L, Lei C and Luo Y: Contrast-enhanced ultrasound in diagnosis of primary hepatic angiosarcoma. J Med Ultrason (2001) 44: 267-270, 2017.
14. Shin JH, Baek JH, Chung J, Ha EJ, Kim JH, Lee YH, Lim HK, Moon WJ, Na DG, Park JS, et al; Korean Society of Thyroid Radiology (KSThR) and Korean Society of Radiology: Ultrasonography diagnosis and imaging-based management of thyroid nodules: Revised Korean Society of thyroid radiology consensus statement and recommendations. Korean J Radiol 17: 370-395, 2016.

15. Saitta C, Raffa G, Alibrandi A, Brancatelli S, Lombardo D, Tripodi G, Raimondo G and Pollicino T: PIVKA-II is a useful tool for diagnostic characterization of ultrasound-detected liver nodules in cirrhotic patients. Medicine (Baltimore) 96: e7266, 2017.

16. Bhartia B, Ward J, Guthrie JA and Robinson PJ: Hepatocellular carcinoma in cirrhotic livers: Double-contrast thin-section MR imaging with pathologic correlation of explanted tissue. AJR Am J Roentgenol 180: 577-584, 2003.

17. Al-Hilli Z, Strajina V, McKenzie TJ, Thompson GB, Farley DR and Richards ML: The role of lateral neck ultrasound in detecting single or multiple lymph nodes in papillary thyroid cancer. Am J Surg 212: 1147-1153, 2016.

18. Haugen BR, Alexander EK, Bible KC, Doherty GM, Mandel SJ, Nikiforov YE, Pacini F, Randolph GW, Sawka AM, Schlumberger M, et al: 2015 American Thyroid Association management guidelines for adult patients with thyroid nodules and differentiated thyroid cancer: The American Thyroid Association guidelines task force on thyroid nodules and differentiated thyroid cancer. Thyroid 26: 1-133, 2016.

19. Fukuoka O, Sugitani I, Ebina A, Toda K, Kawabata K and Yamada K: Natural history of asymptomatic papillary thyroid microcarcinoma: Time-dependent changes in calcification and vascularity during active surveillance. World J Surg 40: 529-537, 2016.

20. Gong B, Liu JD, Ying H, Wang T and Jia M: The diagnostic analysis of high frequency color Doppler ultrasound in thyroid cancer. In: Proceedings of the 2015 International Conference on Medicine and Biopharmaceutical (China). Med Biopharmaceut pp245-250, 2016

This work is licensed under a Creative Commons Attribution-NonCommercial-NoDerivatives 4.0 International (CC BY-NC-ND 4.0) License. 